\title{
Análise das representações sociais sobre avaliação da aprendizagem no discurso de discentes em dois cursos de fisioterapia do estado do Pará Analysis of the social representations on assessment of learning in the students' discourse in two physiotherapy courses in the state of Pará
}

\author{
Renato da Costa Teixeira ${ }^{1}$ \\ teixeirarenato@globo.com \\ Erica Silva de Souza Matsumura² \\ erica.s.souyza@terra.com.br
}

\section{Resumo}

A avaliação da aprendizagem tem uma íntima relação com o tipo de profissional que estamos formando. Um modelo avaliativo baseado em provas tem a função de manutenção do status quo. Este estudo teve o propósito de analisar as representações sociais de discentes de dois cursos de fisioterapia do estado do Pará em relação à avaliação da aprendizagem. Para isso, utilizou-se a Técnica de Associação Livre de Palavras e o software EVOC 2005. No núcleo central, a principal palavra encontrada foi conhecimento, enquanto no núcleo periférico encontrou-se repetição de palavras que representam os instrumentos de avaliação. Os achados mostram que há uma distorção do sentido da avaliação, comprometendo a formação crítica e reflexiva conforme determinam as normas em vigor.

Palavras-chave: Avaliação da aprendizagem, Educação superior, Fisioterapia, Representações sociais, Ensino em saúde

\begin{abstract}
The assessment of learning has an intimate connection with the type of professional we are preparing. An evaluation model based on tests plays the role of maintaining the status quo. This study has aimed to analyze the social representations for learners of two courses of physical therapy in the state of Pará about the assessment of learning. In this regard, we have used the technique of free association of words and the software EVOC 2005. In the central core knowledge has been the main word found, while in the peripheral nucleus, it has been found repetition of words which represent the assessment tools. The findings show that there is a distortion of the assessment sense, which affects the critical and reflective professional training as the current regulations establish.
\end{abstract}

Keywords: Assessment of learning, Higher education; Physiotherapy; Social representation; Health education

\footnotetext{
${ }^{1}$ Doutor em Educação. Docente do programa de Pós-graduação Mestrado em Ensino em Saúde na Amazônia da UEPa.

${ }^{2}$ Docente do curso de Fisioterapia da Esamaz. Mestranda em Ensino em Saúde na Amazônia da UEPa.
} 


\section{Introdução}

\section{Sobre a avaliação}

Segundo Luckesi (2006), a denominação avaliação da aprendizagem é bem recente, sendo atribuída a Ralph Tyler, que se dedicou à questão de um ensino que fosse eficiente. Até então, segundo Tyler (1975), dentro da visão do ensino, eram usados mais os termos provas e exames, levando esse autor a afirmar que o sistema de exames utilizados em escala mundial era uma forma de controle político, social e cultural, e não uma forma de medir a capacidade intelectual.

Esse controle sempre foi muito evidente e, segundo Teixeira (2010), pode ser evidenciado nas instruções de d. Francisco Moreno, trazidos por Herrera (1997), sobre os métodos de ensino que deveriam ser observados nos colégios religiosos no século XVIII.

Para seguir o método jesuítico de ensino (Ratio Studiorum), era recomendado que os estudantes, após o período de férias escolares, deveriam submeter-se a exames rigorosos, para que pudessem continuar seus estudos.

As concepções de avaliação, assim como aquelas relativas ao ato de ensinar, foram sofrendo mudanças, ao longo da história. Os modelos e concepções de avaliação utilizadas no Brasil foram importados de modelos utilizados em outros países e tiveram uma evolução que obedeceram aos diversos momentos pelo quais passou a educação em nosso país. A avaliação enquanto elemento do processo ensino-aprendizagem obedece a um modo de pensar a pedagogia. Podem-se identificar, nos dias atuais, diferentes modos do pensar pedagógico na prática educativa, que aparecem com maior ou menor intensidade em nosso dia a dia.

Segundo Luckesi (2006), os jesuítas, nas normas para orientação dos estudos, tanto nas classes inferiores como nas superiores, tinham uma atenção especial com o ritual das provas e exames, que eram solenes e realizados em ocasiões especiais, perante bancas examinadoras.

Posteriormente, com a gradativa saída das ordens religiosas e a ascensão da burguesia, a educação e a avaliação foram sendo substituídas por modelos menos rígidos, porém, ainda centradas no conteúdo, realizadas em momentos terminais. 
Com o surgimento do movimento da Escola Nova (século $X X$ ), a avaliação passou a recair também sobre as habilidades e a valorizar a autoavaliação.

Na década de 1960, após a ascensão dos militares ao poder, com a necessidade de alfabetização de massas, desenvolveu-se no Brasil a visão tecnicista de educação, na qual a avaliação passa a ser relacionada diretamente com os objetivos e não mais com os conteúdos, realizada através de provas objetivas, de forma exagerada, a fim de medir os resultados.

Paralelamente, surgiram pensadores como Paulo Freire que buscavam discutir a relação entre a educação (e seus componentes) e a sociedade. Nessa concepção, a avaliação permite aos sujeitos (docente e discente) refletirem sobre o processo de ensino e/ou aprendizagem.

Segundo Pivetta (2006), em relação ao ensino superior, na atualidade, a docência vem sendo exercida por profissionais de diversas áreas de conhecimento, que, em sua maioria, não têm a devida preparação para esse ofício. Essa falta de preparo não se refere apenas ao "que-fazer" docente, mas também a tudo o que envolve o ato de ensinar, conforme afirma Fernandes (1999, p.3):

[...] não se pode falar em uma pedagogia universitária, mas sim pedagogias universitárias, quanto em relação aos diferentes campos profissionais. Vive-se, assim, uma tensão constante entre o específico e o geral, entre o indivíduo e o coletivo, que interagem em processos, em decisões pedagógicas na instância de cada curso e que adentram na formação do professor e nas suas práticas pedagógicas, sem que, na maioria das vezes, se tenha consciência dessas tensões e arbitrariedades presentes na estrutura de poder de cada profissão.

Segundo Nóvoa (apud Melo, 2011), a formação do docente não é construída por acumulação de cursos, conhecimento ou de técnicas, mas através de um processo de reflexão sobre nossas práticas. Rausch e Silva (apud Freitas; Aguiar, 2011, p. 16.235) afirmam ainda que "A transformação da prática do professor não se dá meramente por acúmulo teórico de transmissão de informações, nem por uma ação mecânica rotineira, mas a partir de um processo de reflexividade do professor".

Em muitas discussões entre profissionais de saúde-docentes, as seguintes dúvidas sempre estão presentes:

$\checkmark \quad$ O que é avaliar? 
$\checkmark \quad$ O que é não avaliar?

$\checkmark \quad$ Qual é a diferença entre testar, medir e avaliar?

Avaliar não é um processo de dar notas, nem tão pouco fazer uma prova ou um exame, nem uma forma de medir os conhecimentos dos discentes. Podemos afirmar que avaliar é:

1) Identificar como os discentes avançam no processo de aprendizagem e de formação profissional, com a finalidade de proporcionar uma formação integral, e não exclusivamente qualificar. O importante não é a nota que se obteve, mas sabermos o quanto se aprendeu e o quanto se necessita aprender;

2) Valorizar a ação educacional tanto do mestre quanto do estudante, pois, no momento em que analisamos os fatores pertinentes ao processo de aprender e procuramos as opções para que esse aprendizado aconteça de forma individual, haverá um crescimento no processo de aprendizagem e na formação profissional, fazendo com que a avaliação sirva de base para uma nova aprendizagem;

3) Processo de reflexão que analisa as causas e fatores que motivaram o desempenho excelente ou não do aluno em seus conhecimentos, habilidades e atitudes, e, a partir dessa identificação, realizar um processo de orientação e de construção do aprendizado, tornando-se uma ação voltada para uma melhoria do processo de aprendizagem.

Muitos confundem ainda avaliar com testar e medir. Existe uma diferença básica entre esses termos, e aqueles que não detêm o conhecimento acerca do ensino pensam ser sinônimos. Podemos verificar a síntese dessas diferenças reproduzidas no Quadro 1.

\begin{tabular}{|l|l|l|}
\hline \multicolumn{1}{|c|}{ MENOS ABRANGENTE } & \multicolumn{1}{|c|}{ MAIS ABRANGENTE } \\
\hline \multicolumn{1}{|c|}{ Testar } & \multicolumn{1}{|c|}{ Avaliar } \\
\hline $\begin{array}{l}\text { Verificar um desempenho } \\
\text { através de situações } \\
\text { previamente } \\
\text { organizadas, chamadas } \\
\text { testes. }\end{array}$ & $\begin{array}{l}\text { Descrever um fenômeno do } \\
\text { ponto de vista quantitativo, } \\
\text { atribuindo valores. }\end{array}$ & $\begin{array}{l}\text { Interpretar } \\
\text { quantitativos e qualitativos } \\
\text { para obter um parecer ou } \\
\text { julgamento de valor, tendo } \\
\text { por base padrões ou } \\
\text { critérios. }\end{array}$ \\
\hline
\end{tabular}

Quadro 1: Diferenças entre Testar, Medir e Avaliar

Adaptado de Haudt, Regina Célia Casaux, 2006 p.291

Revista Educação Online, n. 20, set-dez 2015, p. 17-34 
A medida diz o quanto o aluno possui de determinada habilidade; a avaliação informa sobre o valor dessa habilidade; e o teste, o meio pelo qual colhemos as informações sobre essa habilidade.

Assim, avaliar vai além de testar e medir. O resultado de ambos conduz à avaliação, que tem um caráter de investigação, na qual procuramos entender o porquê das reações e respostas do sujeito que está sendo estudado (o aluno). Assim, o resultado de uma avaliação pode ser expresso em notas, em conceitos ou em relatórios escritos ou orais, mas deve sempre servir ao crescimento do aluno.

Segundo Machado (apud Prandi, 2009), por influência do positivismo, a partir da segunda metade do século XIX, a avaliação foi se afastando de seu caráter diagnóstico, passando a se identificar com o medir. De acordo com Luckesi (2006), ao ser confundida com testagem, a avaliação pode se constituir em mecanismos de exclusão de determinados discentes e/ou grupos de discentes, em detrimento da qualidade do processo avaliativo.

Avaliação enquanto elemento do processo de ensino tem uma íntima relação com o tipo de profissional ou de cidadão que estamos formando. Para Vasconcellos (1994), a escola é usada no sentido de colaborar com a marginalização de grandes setores das camadas populares, na medida em que essas saem da escola com a convicção de que são incompetentes quando a avaliação é usada apenas para classificar.

Nesse sentido, um modelo avaliativo, calcado em provas e testes, que classificam os discentes de acordo com suas notas, tem a função de manutenção do status quo. Já em uma perspectiva libertadora, a avaliação é um instrumento capaz de ajudar o aluno a se construir como cidadão, pois ela está comprometida com o senso crítico, com a sensibilidade social, com a autonomia dos indivíduos, com as "transformações" e "mudanças" nas relações sociais.

O direito a se educar integralmente não pode ser truncado por uma má qualificação em determinada prova ou por não ter atingido uma determinada nota. A avaliação tem que ter o sentido de mediar um nível de conhecimento a outro, a nota ou a qualificação tem que servir de meio para uma nova aprendizagem, assim como as experiências vividas servem de base para novas experiências. 


\section{Sobre a avaliação e a formação do profissional de saúde}

No momento, as Diretrizes Curriculares Nacionais (DCNs) das 14 profissões da saúde apontam para um perfil do egresso generalista, humanista, crítico e reflexivo, aptos a atuar em todos os níveis de atenção à saúde, com ações de promoção, prevenção, recuperação e reabilitação à saúde, com base no rigor científico e intelectual, pautados em princípios éticos.

O artigo 9ำ das DCNs sugere um projeto pedagógico centrado no aluno como sujeito da aprendizagem e apoiado no professor como facilitador e mediador do processo ensino-aprendizagem. Isso pressupõe a utilização de metodologias que tornem o aluno partícipe de seu aprendizado, em contraponto a metodologias tradicionais, nas quais o professor é o detentor do saber e principal elemento do processo ensino-aprendizagem.

Entretanto, não basta mudar as metodologias para atingir o perfil desejado; é necessário, entre outras coisas, que o professor entenda o papel fundamental que exerce a avaliação, pois ela ajudará o aluno a ter uma melhor formação, uma vez que a prática de reflexão em cima do que foi feito, permite alcançar objetivos mais amplos. Quando um aluno conhece seus os erros, é possível corrigi-los a tempo.

De acordo com Masetto (2011), metodologias de ensino e modelos de avaliação tradicionais não poderão ter lugar na formação de um profissional crítico e reflexivo. É preciso que se utilizem metodologias ativas, valorizando e incentivando a participação dos alunos em seu processo de aprendizagem e em sua formação.

Em relação à avaliação, Hoffmann (1995) defende que ela deverá gerar questionamentos que irão se transformar em ações, que, por sua vez, nos trarão novas inquietações e assim sucessivamente. Por essa forma de ver, os erros e acertos dos alunos passam a ser vistos como episódios altamente significativos, levando a uma reflexão e aquisição de aprendizagem. Nesse sentido, a avaliação deixa de ser o momento final do processo ensinoaprendizagem, para se transformar numa busca permanente do alcance dos objetivos, tanto do aluno como do professor, que irão levar a outras reflexões e assim por diante, ou seja, transforma-se numa via de mão dupla. 
Segundo Teixeira e Muniz (2007), diversos autores têm se preocupado em definir avaliação. Analisando essas definições, os autores resumiram o significado de avaliação em:

a) Avaliação visa a observar mudanças no comportamento do aluno (Tyler, Bloon, Sant'anna e Taba);

b) Avaliação implica em julgamento (Ebel, Thorndike, Hagen, e Silva);

c) Avaliação é uma forma de controle de qualidade (Bloon, Hasting e Madaus, Zaya, Fernandez et al);

d) Avaliação é um processo contínuo (Marques e Gronhund);

e) Avaliação é uma reflexão e tomada de decisão (Hoffmann, Castro e Stufflebeam);

f) Avaliação trata de um juízo de valor (Sarabi, Penna Firme, Bradfield, Moredock, Luckesi, Popham, Ausbeck, Novak e Hanesian);

g) Avaliação é evidenciada através de coleta de evidências (Ragan e Fleming);

Porém, temos percebido entre os alunos do curso de graduação em fisioterapia e nos alunos das disciplinas Metodologias de Ensino e Educação, em Enfermagem do Mestrado Associado em Enfermagem e Educação em Saúde na Amazônia, do Mestrado Profissional em Ensino em Saúde na Amazônia, da Universidade do Estado do Pará, que as distorções do sentido da avaliação ainda vigoram.

\section{Sobre as representações sociais}

Para Alves-Mazzotti (2008), as questões e eventos que surgem no horizonte social exigem, de alguma maneira, que busquemos compreendê-los, aproximando-os daquilo que já conhecemos, usando palavras que fazem parte de nosso repertório. Tanto em casa, quanto no trabalho ou com os amigos, somos chamados a nos manifestar sobre diversas situações. Nessas manifestações, procuramos dar explicações, fazer julgamentos e tomamos posições.

Essas interações sociais criam os chamados universos consensuais, nos quais produzimos novas representações, que logo são comunicadas e passam a fazer parte desse universo, não mais como simples opiniões, mas como verdadeiras teorias do senso comum, facilitando a comunicação e orientando condutas. 
A sociologia busca explicar esse fenômeno através das representações sociais. Serge Moscovici (2011), psicólogo social radicado na França, foi o precursor da teoria das representações sociais. Esse autor afirma que as representações sociais são elaboradas a partir de conversações, no universo comum, na convivência cotidiana, mostrando que elas estão presentes em todos os locais aonde as pessoas interagem informalmente, servindo à função de orientar seus comportamentos e suas comunicações. O estudo das representações sociais investiga como se formam e como funcionam os sistemas de referência que utilizamos para interpretar os acontecimentos da realidade cotidiana.

De acordo com Abric (2001,) a representação social é composta por um conjunto de informações, crenças, valores e atitudes acerca de um objeto social e pode ser organizada, estruturada e constituída em um sistema sociocognitivo. Já Moscovici (2011) considera que toda representação social nos ajuda a resolver o problema geral de saber quando interpretar uma mensagem como significante em relação a outras e quando vê-la como um acontecimento fortuito ou casual. Essas se organizam em torno de um núcleo central, que tem caráter estável e organizador e ao redor do qual se dispõem os elementos periféricos que são flexíveis e mutáveis. Para Duveen (2011), as representações sociais entram para o mundo comum e cotidiano, em que habitamos e discutimos com nossos amigos e colegas, e circulam na mídia que lemos.

As representações sociais possuem duas funções: dar forma, localizar em uma categoria, colocar como modelo algo que ainda não conhecemos (função convencionalista) e impor sobre nós uma força irresistível (função prescritiva).

A esse respeito, Moscovici (2011) nos mostra que, antes de ver e ouvir a pessoa, nós já a julgamos, nós já a classificamos e criamos uma imagem dela. Os mais interessantes são aqueles julgamentos em que os acusados são apresentados como culpados, malfeitores e criminosos, e o processo apenas serve para confirmar um veredito pré-estabelecido.

As representações sociais são elaboradas em três fases: a) fase científica: momento inicial em que são elaboradas; b) fase representativa: 
momento em que se difundem em uma sociedade; c) fase ideológica: quando são apropriadas por um partido ou uma escola de pensamento.

Moscovici (2011) relata dois processos que geram as representações sociais: (1) a ancoragem: ocorre quando classificamos ou damos nome a coisas que não são classificadas e que não possuem nome, pois ainda são estranhas e ameaçadoras para nós; (2) a objetivação: ocorre quando teorias incomuns que ninguém levava a sério passam a ser normais, críveis e explicadoras da realidade algum tempo depois.

As pessoas aceitam, acima de tudo, aqueles fatos ou percebem aqueles comportamentos que confirmam suas crenças habituais, isso mostra que a razão das representações sociais é tornar-nos familiar algo que não nos é, ou seja, a motivação para criarmos ou aceitarmos uma representação social é criarmos uma ponte entre o estranho e o familiar.

\section{Percurso metodológico}

Problema da pesquisa: Quais as representações sociais presentes nos discursos de discentes de cursos de fisioterapia que utilizam metodologias tradicionais de ensino no estado do Pará?

Objetivo: Analisar as representações sociais sobre avaliação da aprendizagem presente no discurso de discentes de dois cursos de fisioterapia no estado do Pará.

Para atingirmos os objetivos e respondermos ao problema desta pesquisa, realizamos um estudo exploratório, analítico-descritivo, através da análise das representações sociais, utilizando-se, para tal, da metodologia prescrita por Moscovici através do software Evoc 2005. Esse software permite identificar os elementos pertencentes ao provável núcleo central da representação, bem como os elementos periféricos, a partir de dois critérios: a frequência média de ocorrência das palavras e o grau de importância atribuído a elas, por meio do lugar ocupado na ordem de evocação.

O presente projeto foi aprovado pelo Comitê de Ética em Pesquisa do Campus II/CCBS/UEPa, (Protocolo oo 312.835 de 14/06/2013), atendendo às normativas éticas emanadas pela Resolução 466/2012 do Conselho Nacional de Saúde, a Declaração de Helsinque, o Código de Nuremberg, através de seu registro na Plataforma Brasil. 
Inicialmente, buscamos a aprovação dos coordenadores dos dois cursos, para que pudéssemos ter acesso aos discentes nas salas de aula. A amostra foi composta por todos os discentes que estivessem dispostos a responder ao questionário, nos dois cursos de fisioterapia que adotam metodologias tradicionais no estado do Pará, um público e um privado, e que concordassem em participar através da assinatura do Termo de Consentimento Livre e Esclarecido.

Após concordarem em participar, os pesquisados preencheram um questionário, no qual se identificavam e, após o preenchimento, foi utilizada a Técnica da Associação Livre de Palavras, que consiste em estimular o sujeito a associar entre três e cinco palavras a um termo indutor (palavra ou expressão), sugerido pelo pesquisador. Essa técnica envolve ainda a hierarquização das palavras evocadas, em ordem crescente de importância, e a seleção daquela considerada a mais importante. Para tal, foi pedido ao participante da pesquisa que buscasse de forma livre cinco termos ou expressões que surgissem em sua mente quando falamos em avaliação da aprendizagem. Após terem sido evocadas as palavras, foi solicitado que as enumerassem de 1 a 5 , em ordem de importância, sendo o 1 a mais importante, e 5 a menos importante, de acordo com a metodologia prescrita por Vergés (2006).

A partir dessas respostas, foi elaborado o dicionário léxico das repostas, no qual se procurou eliminar termos ou expressões repetidas ou similares, através da escolha de um só que representasse todos.

Os dados coletados foram armazenados em uma planilha Excel e posteriormente submetidos à análise através do software Evoc 2005, no qual se buscaram as palavras que representassem 0 núcleo central das representações sociais (mais frequentes e mais importantes) e as que representassem o núcleo periférico (menos frequentes e menos importantes). As respostas foram expostas em um quadro de quatro casas, no qual ficou evidenciada a distribuição dos termos evocados, estando no quadrante superior esquerdo o núcleo central das representações.

Após a análise feita pelo software, foram comparadas as respostas com o que dizem os teóricos a respeito do tema. Os dados gerais foram armazenados igualmente em uma planilha Excel e demonstrados através de gráficos. 


\section{Resultados}

A amostra foi composta de 190 discentes (92 da IES pública e 98 da IES privada), dos quais 125 do sexo feminino e 65 do sexo masculino, como pode ser verificado no Gráfico 1.

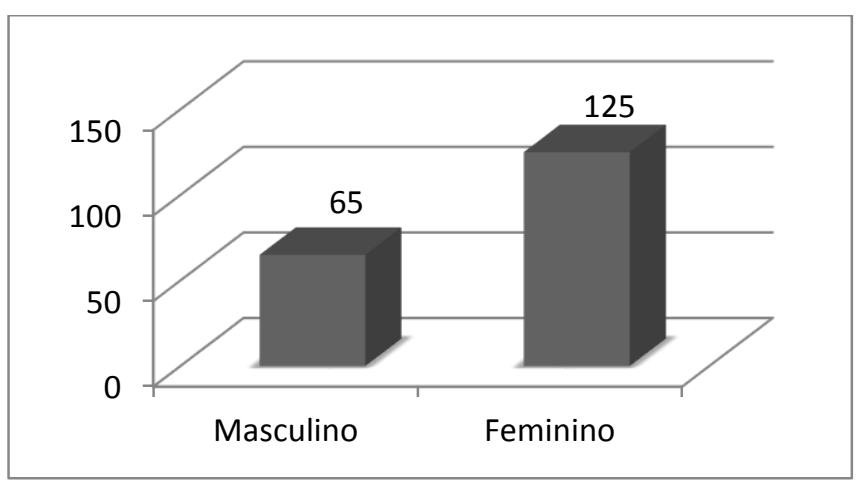

Gráfico 1: distribuição de gênero entre a amostra estudada Fonte: autor

A idade média geral dos discentes foi de $23,88 \pm 6,77$ anos $(21,75$ na IES pública e 25,77 na IES privada).

Os participantes evocaram um total de 929 palavras, das quais 283 diferentes $(30 \%)$, com uma frequência mínima para análise de 5 , uma frequência intermediária de 9 e um ranqueamento médio de 2,9. A análise das representações sociais seguiu a metodologia proposta por Vergé (2006).

\begin{tabular}{|c|c|c|c|c|c|c|}
\hline & Ranque $<2,9$ & & & Ranque $\geq 2, \subseteq$ & & \\
\hline & Termo & Frequência & Ranque & Termo & Frequência & Ranque \\
\hline & Conhecimento & 61 & 2,262 & Aluno & 14 & 3,143 \\
\hline & Conteúdo & 11 & 2,727 & Debates & 10 & 3,000 \\
\hline & Dedicação & 10 & 2,200 & Faculdade & 22 & 3,591 \\
\hline & Educação & 29 & 2,345 & Inteligência & 9 & 3,556 \\
\hline$\Lambda$ & Ensino & 16 & 2,625 & Interação & 10 & 4,200 \\
\hline$\frac{\pi}{0}$ & Estudo & 32 & 2,125 & Metodologia & 26 & 3,154 \\
\hline$\stackrel{0}{0}$ & Pesquisa & 20 & 2,900 & Notas & 32 & 4,031 \\
\hline$\stackrel{\oplus}{2}$ & Professor & 42 & 1,810 & Provas & 58 & 3,638 \\
\hline$\Phi$ & Prova-prática & 18 & 2,722 & Seminários & 10 & 3,800 \\
\hline 亡4 & Qualidade & 14 & 2,000 & Testes & 19 & 3,474 \\
\hline$\omega$ & Termo & Frequência & Ranque & Termo & Frequência & Ranque \\
\hline
\end{tabular}




\begin{tabular}{|l|l|l|l|l|l|}
\hline Aprender & 7 & 2,571 & Aprendizagem & 7 & 3,286 \\
Atenção & 5 & 2,800 & Avaliação & 8 & 3,625 \\
Compromisso & 8 & 2,000 & Carreira & 8 & 3,125 \\
Importante & 5 & 2,400 & Inteligência & 9 & 3,556 \\
Interesse & 7 & 2,429 & Livros & 6 & 3,000 \\
Memorização & 6 & 2,833 & Pontualidade & 7 & 3,857 \\
Necessária & 5 & 2,000 & Sabedoria & 5 & 3,600 \\
Prova teórica & 7 & 2,429 & & & \\
Responsabilidade & 6 & 2,000 & & & \\
\hline
\end{tabular}

Quadro 2: Evocação dos discentes sobre avaliação da aprendizagem

Núcleo Central: Ranque < 2,9 e Frequência $\geq 9$; Núcleo Periférico: Ranque $\geq 2,9$ e Frequência $\geq 9$ ou Ranque $<2,9$ e $5 \leq$ Frequência $\leq 9$.

Fonte: autor

No Quadro 2, podemos verificar as palavras evocadas pelos discentes que se localizam no Núcleo Central e Periférico. Segundo Sá (1996), as palavras do quadrante superior esquerdo tendem a representar o Núcleo Central, sendo as mais frequentes e mais prontamente evocadas. No quadrante superior direito, encontramos as palavras que dão sustentabilidade ao núcleo central e confirmam o elo com ele. São importantes, mas fazem parte do quadrante periférico das representações.

No quadrante inferior esquerdo, encontramos os elementos intermediários das representações sociais, que, embora apresentem baixa frequência, não diminuem sua importância e podem revelar indícios da existência de um subgrupo minoritário, portador de uma representação diferenciada (ABRIC, 2001). No último quadrante (inferior direito), as palavras encontradas são responsáveis pela função reguladora e por resguardar a estabilidade do núcleo.

Percebe-se que 0 termo mais evocado pelos discentes foi conhecimento com uma frequência de 61 repetições e uma ordem de importância de 2,262 (em que 1 é o mais importante e 5 o menos importante). O termo professor teve um ranqueamento mais importante $(1,810)$, no entanto, foi evocado 42 vezes. Ainda no Núcleo Central, nos chama a atenção os termos da pesquisa evocada 20 vezes (grau de importância de 2,90) e prova prática evocada 18 vezes (grau de importância de 2,722).

Na periferia, ainda estão presente significativamente termos como Notas $(32-4,031)$, Provas $(58-3,638)$, Seminários $(10-3,800)$, Testes $(19-$ $3,974)$, Memorização $(6-2,833)$ e Prova-teórica $(7-2,429)$, o que 
caracteriza um desvirtuamento do sentido da avaliação. No total, as palavras que representam instrumentos de avaliação foram evocadas 142 vezes.

A relação entre as palavras vistas no núcleo central de nosso estudo nos mostra que o professor ensina o conteúdo e se utiliza da pesquisa ou da prova prática para buscar o conhecimento do aluno que estuda com dedicação e isso seria a educação de qualidade.

Em uma análise somente da IES pública, obtivemos no Núcleo Central: conhecimento; educação; estudo e prática. Já na IES privada, obtivemos: conhecimento; educação; estudar e professor.

No Núcleo periférico da IES pública, encontramos: metodologia; notas; pesquisa; provas; aprender; carreira; compromisso; discussão; ensino; memorização; necessária e qualidade. Na IES privada, encontramos: aluno; faculdade; notas; provas; testes; dedicação; disciplina; ensino; pesquisa e qualidade.

A partir da análise do Núcleo Central, nos propusemos a realizar a análise semântica das palavras evocadas, seguindo a mesma metodologia adotada por Guimarães et al (2015), alocando-se as palavras em três categorias segundo seu caráter: pedagógico, cognitivo ou socioafetivo. No quadro 3, podemos visualizar essa categorização semântica.

\begin{tabular}{|l|c|l|c|l|c|}
\hline \multicolumn{2}{|c|}{ Pedagógica } & \multicolumn{2}{c|}{ Cognitiva } & \multicolumn{2}{c|}{ Socioafetiva } \\
\hline Palavras & $\mathrm{f}$ & Palavras & $\mathrm{f}$ & Palavras & $\mathrm{f}$ \\
\hline Professor & 42 & Conhecimento & 61 & Qualidade & 14 \\
Estudo & 32 & & & Dedicação & \\
Educação & 29 & & & & \\
Pesquisa & 20 & & & & \\
Prova prática & 18 & & & & \\
Ensino & 16 & & & & \\
Conteúdo & 11 & & & \\
\hline
\end{tabular}

O campo semântico pedagógico se sobressaiu quantitativamente em relação às demais, diferentemente do estudo de Guimarães et al, no qual o campo semântico socioafetivo foi o que mais se sobressaiu. Nesse estudo, foram encontradas as palavras conhecimento, estudo e prova coincidente ao nosso estudo, no entanto, a metodologia utilizada foi diferente.

Alves e Pimenta (2013), ao estudarem as representações sociais de estudantes de licenciatura utilizando-se da mesma metodologia utilizada por nós, encontrou no núcleo central as palavras prova, conhecimento, estudo e 
necessária. Dessas quatro palavras, três estavam em nosso núcleo central e uma no núcleo periférico. Além dessas, foram encontradas no núcleo periférico coincidentes ao nosso estudo as palavras aprendizagem, conteúdo e dedicação.

Para Camargo (1997), em um estudo a respeito do discurso sobre a avaliação escolar em alunos universitários, as representações sociais dos discentes acerca da avaliação reportam a "disciplinação" e "dominação", o que não foi encontrado em nosso estudo.

Reis, Matos e Prado (2005), em seu trabalho sobre as representações sociais dos discentes de enfermagem em relação à avaliação da aprendizagem, encontraram avaliação como "reprodução de conteúdo", "medida do conhecimento", "valorização do erro", que podem ser considerados similares ao nosso estudo, uma vez que encontramos conteúdo e conhecimento.

A Lei de Diretrizes e Bases da Educação Nacional, ao dar as diretrizes para a educação brasileira, deu autonomia às universidades para decidir sobre suas questões acadêmicas, dando liberdade para que elas traçassem suas diretrizes. Com relação à avaliação do desempenho dos alunos no ensino superior, exige apenas a obrigatoriedade de frequência, salvo em casos de educação a distância.

Em relação às instituições estudadas, o Regimento Interno do Centro de Ciências Biológicas e da Saúde da Universidade Pública em seu artigo 70 preconiza que:

A avaliação da aprendizagem, contínua e cumulativa, compreenderá, de acordo com a natureza das disciplinas, um conjunto de atividades: aulas teóricas, seminários, planejamento, execução e avaliação de pesquisa, trabalhos de campo, estágios supervisionados ou equivalente; leituras programadas; trabalhos especiais; provas orais ou escritas, prova prática, estudo de caso, pesquisa bibliográfica, trabalho individual e/ou equipe; de acordo com a natureza das disciplinas e outras previstas nos planos de ensino.

Portanto, os professores podem enriquecer o processo avaliativo criando várias formas de avaliação que levem em consideração o raciocínio do aluno, sua capacidade de produzir novos conhecimentos, o desenvolvimento do aluno para atingir esse conhecimento e as atitudes em sala de aula. 
Já a outra instituição não possui Regimento Interno disponível para consulta, nem mesmo guia acadêmico, e os docentes desconhecem qualquer norma da instituição referente à avaliação da aprendizagem.

Contudo, a presença ou não de normas institucionais em relação à avaliação não impediu que os alunos correlacionassem avaliação com os instrumentos usados pelos professores, o que foi visto na análise do núcleo periférico das evocações dos alunos, podendo indicar que pode estar havendo um desvirtuamento do sentido da avaliação por parte dos docentes, ao se utilizarem muito de determinados instrumentos.

Vasconcelos (1994) aponta que as distorções que ocorrem no sentido da avaliação se fazem por diversos fatores, entre os quais cita:

a) Em razão de sua formação deficitária (o professor não tem o domínio de como o aluno se desenvolve ou de como aprende) e, no entanto, quer cumprir sua tarefa;

b) Para garantir sua autoridade;

c) Como instrumento de pressão, a partir do condicionamento dos discentes já deformados pela ênfase à nota;

d) Por ingenuidade, mantendo o mesmo esquema seguindo as regras;

e) Por convicção, por achar que os discentes precisam estar preparados para estágios mais fortes no futuro;

f) Por comodidade, para não "mexer com muita coisa";

g) Por pressão, pois é cobrado pela instituição ou por colegas a fazer da avaliação um instrumento tradicional.

Pereira (2011 apud Freitas; Aguiar), afirma que existe uma inércia por parte dos docentes diante da necessidade de mudança, pois nunca fazem uma reflexão sobre o que estão fazendo, levando a vida tomando todas as decisões que lhe são exigidas no dia a dia (dar notas, controlar a ordem).

De acordo com Isaia e Bolzan (2004), o início da trajetória profissional docente para os profissionais de saúde é precário, uma vez que devem assumir novos encargos, respaldados não em conhecimentos adquiridos na academia, mas em modelos internalizados em sua formação inicial profissional. Para Grillo e Fernandes (2003), esse fato traz consigo consequências bem negativas, uma vez que, sendo um "ofício sem saberes", fortalece a crença de que para ensinar é suficiente saber o conteúdo, ter talento, bom senso, 
intuição, experiência ou cultura. Essa crença vai sendo transmitida de docente para adiante, assim como de pai para filho. Espelhamo-nos em nossos professores ao nos tornarmos professores.

\section{Conclusão}

O regimento interno de uma das duas instituições de ensino pesquisadas coloca que 0 ato de avaliar pode ser realizado por diversos métodos e utilizando modelos distintos, não devendo ser nunca terminal, enquanto na outra é desconhecido até pelos docentes.

No entanto, ao analisarmos as representações sociais de discentes de dois cursos de fisioterapia, no estado do Pará, pudemos verificar que ainda existe um desvirtuamento do significado de avaliação para eles. Os achados confirmam que há uma distorção do sentido da avaliação para os discentes, o que pode estar influenciando o perfil de formação do profissional humanista, crítico e reflexivo, conforme determinam as Diretrizes Curriculares Nacionais.

Faz-se necessário que as instituições ofereçam cursos e treinamentos a seus professores sobre a temática, para que eles possam repensar suas práticas avaliativas, rever seus procedimentos e trabalharem suas avaliações em uma perspectiva de construção do conhecimento, e não simplesmente de medição do conhecimento.

\section{Referências bibliográficas}

ABRIC, J. C. O estudo experimental das representações sociais. In: JODELET, D. (Org.). As representações sociais. Rio de Janeiro: UERJ; 2001. p. 155-72.

ALVES-MAZZOTTI, A. J. Representações sociais: aspectos teóricos e aplicações à Educação. Revista Múltiplas Leituras, v.1, n.1, p. 18-43, jan-jun 2008.

ALVES, I. M. S.; PIMENTA, M. A. A. Avaliação da aprendizagem no ensino superior: representações sociais de estudantes de licenciatura. Quaestio, v. 15, n. 2, p. 221-240, dez 2013.

CAMARGO, A. L. C. O discurso sobre a avaliação escolar do ponto de vista do aluno. Revista da Faculdade de Educação, São Paulo, v. 23, n.1, jan 1997.

DUVEEN, G. O poder das ideias. In MOSCOVICI, S. Representações Sociais: investigações em psicologia social. 8ª̣ed. Petrópolis: Vozes, 2011. p.7-28

FERNANDES, C. M. B. Sala de aula universitária: ruptura, memória educativa, territorialidade. O desafio da construção pedagógica do conhecimento. 1999, 
Porto Alegre. Tese (Doutorado em Educação) - Universidade Federal do Rio Grande do Sul. Porto Alegre, 1999.

FREITAS, T. C. S.; AGUIAR, N. M. S. Produção científica: representações sociais de docentes do ensino superior na área da saúde. In: SEMINÁRIO INTERNACIONAL DE REPRESENTAÇÕES SOCIAIS, SUBJETIVIDADE E EDUCAÇÃO, I, 2011. Curitiba. Anais ... Curitiba: Editora Champanhat, 2011. p. 16.233-16.238

GRILO, M.; FERNANDES, C. M. B. Metodologia do ensino superior: um olhar por dentro. In: MOROSINI, M. (Org.) Enciclopédia de pedagogia universitária. Porto Alegre: FAPERGS/RIES, 2003. p.229-239.

GUIMARÃES, C. M. P. et al. As representações sociais da avaliação da aprendizagem Segundo os licenciandos em matemática da UFPE. Disponível em:

<https://www.ufpe.br/ce/images/Graduacao_pedagogia/pdf/2008.2/as\%20repre sentaes\%20sociais\%20da\%20avalia0\%20da\%20aprendizagem\%20segun.pdf> . Acesso em 26/02/2015.

HAUDT, R. C. C. Curso de didática geral. 8ed. São Paulo: Ed.Ática, 2006.

HERRERA, J. Interrogar o examinar: un enfoque sobre la evaluación en el medio educativo. 2ed. Santafé de Bogotá: Magistério, 1997.

HOFFMANN, J. Avaliação: mito e desafio. Porto Alegre: Educação e Realidade, 1995.

ISAIA, S. M. A.; BOLZAN, D. P. V. Formação do professor do ensino superior: um processo que se aprende? Revista educação, v.29, n.2, p.121-133, 2004.

LUCKESI, C. C. Avaliação da aprendizagem escolar: estudos e proposições. São Paulo: Cortez, 2006

MASETTO, M. T. Inovação curricular no ensino superior. Revista e-curriculum, v.7, n.2, ago 2011. Disponível em:

$<$ http://revistas.pucsp.br/index.php/curriculum>. Acesso em 17/10/2013.

MELO, M. M. Formação docente e representação social. In: SIMPÓSIO BRASILEIRO DA ANPAE, XXV, 2011, São Paulo. Anais ... São Paulo: Biblioteca ANPAE, Série Cadernos, n.11, 2011. p. 37-43.

MOSCOVICl, S. Representações sociais: investigações em psicologia social. 8ed. Petrópolis: Vozes, 2011.

PIVETTA, H. M. F. Concepções de formação e docência dos professores do curso de fisioterapia do Centro Universitário Franciscano. 2006, Santa Maria. Dissertação (Mestrado em Educação) - Programa de Pós-graduação em Educação - Universidade Federal de Santa Maria. Santa Maria, 2006.

PRANDI, L. R. Tendências do processo didático-pedagógico no ensino superior na contemporaneidade. Akrópolis Umuarama, v. 17, n. 3, p. 137-142, jul-set 2009.

REIS, D. C.; MATOS, E. M.; PRADO, M. L. Representações sociais dos discentes de um curso de graduação em enfermagem sobre a avaliação no processo ensino-aprendizagem. Revista Mineira de Enfermagem, v. 9, n.3, p.187-192, jul-set 2005. 
SÁ, C. P. Núcleo central das representações sociais. Petrópolis: Vozes, 1996.

TEIXEIRA, R. C. Projeto Pedagógico dos cursos de Fisioterapia da região Norte: (des)caminhos da aderências, potencialidades e fragilidades. 2010, Rio de Janeiro. Tese (Doutorado em Educação) - Pontifícia Universidade Católica do Rio de Janeiro. Rio de Janeiro, 2010.

UEPA, 2007. v.1.

; MUNIZ, J. W. C. Avaliar pela pesquisa. Belém: Editora da

TYLER, R. Princípios básicos de currículo e ensino. Porto Alegre: Editora

Globo, 1975

VASCONCELLOS, C. S. Avaliação, concepção dialética-libertadora do processo de avaliação escolar. 4ª ed. São Paulo: Libertad, 1994.

VERGÉS, Pierre. Ensemble de programmes permettant l'analyse des evocations - EVOC 2005, Version June 2006, Provence, France, June, 2006. 